\title{
A Strategy For Promoting Business-It Fusion To Enhance Management Of Enterprise Applications
}

Than Lam, Lockheed Martin Corporation Ronald Black, University of Phoenix

\begin{abstract}
This paper is based upon a research study conducted to determine the significance of managerial leadership practices in a corporation's transformation during the period from 2004 to 2006. The study attempted to discover how business-IT fusion enhances organizational performance. The study answered two questions: how managerial leadership practices effectively advance businessIT fusion of an inclusive and collaborative organization and how business-IT fusion affects risks and profitability. The intention of this study was to contribute to the field of management of information technology grounded on propositions involving organizational development roles, IT governance, and collaborative organizations. Triangulated inquiry from documents and a survey of 24 participants who included 2 women and 22 men comprising a chief information officer, 7 functional managers, 8 project managers, and 8 engineers of a corporation in the northeastern United States confirmed the propositions. The findings indicated that horizontal integration has begun in transition from being separate toward becoming collaborative. This paper will reveal how disparate images that are subculture bound could be enhanced by collaborative and integrative leadership practices. Moreover, the horizontal integration of common financial and technical applications allows work to be transferred across different locations, thus reducing risks and increasing return on investment. This paper will present a collaborative and integrative model integrating organizational development roles, IT governance, and relationship management across organizational settings for transforming effective business-IT fusion.
\end{abstract}

Keywords: Management of Information Technology, Business-IT Fusion, Horizontal Integration, IT Governance, Organizational Development Roles, Collaborative Organizations, Managerial Leadership

\section{INTRODUCTION}

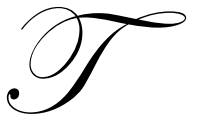

he business-information technology (IT) alignment is a linear process that does not provide synergy or effective solutions to meet a rapidly changing environment (Britt, 2002; A. Evans, 2003; N. Evans, 2004a, 2004b; N. Evans \& Hoole, 2005). According to Britt, many organizations treat business plans as primary and technology plans as secondary. A project life cycle can last from 3 to 30 years while a new technology can be introduced every year. If a business plan is complete first and IT supports the business plan, this practice is not agile enough to take advantage of new technologies and opportunities (Britt). One recommended solution is business-IT fusion.

Business-IT fusion relates to both the organization and the strategy achieved by innovations in IT that fuse business strategy and IT outcomes (Britt, 2002). The key to successful fusion is that the outcomes are realistic and measurable. Britt and N. Evans and Hoole (2005) asserted business-IT fusion must be part of corporate and operational strategies and must be achieved at all levels of the organization. Britt further posited business-IT fusion requires business and IT to work together in a unified way and fusion is the catalyst for competitive advantage that brings "enormous quantities of energy" (p. 4). 
Corporations need strong leadership to create new strategies that promote business-IT fusion and strong management to execute the fusion and meet the changing demands of the environment and key stakeholders. Adapting to changes allows organizations to reposition and strengthen themselves toward the future (Bowditch \& Buono, 2001). From this managerial leadership perspective, two questions that arise are how managerial leadership practices effectively advance business-IT fusion of an inclusive and collaborative organization and how business-IT fusion affects risks and profitability.

Organizations today have independent information technologies, lines of business, and working cultures. Each product has its own IT applications and processes. Organizations have different IT subcultures (Schein, 2004) and geographical locations throughout the United States. To satisfy customers and stakeholder relationships and to enhance its competitive advantage, the organization must integrate its organizational units into a single enterprise to achieve common systems, applications, and processes. This horizontal integration is the consolidation of product lines, financial systems, and engineering applications and processes. The goal is to reduce discrepancies, eliminate redundancies, and improve organizational performance.

N. Evans and Hoole (2005) revealed the main reasons for business-IT nonfusion are poor communication, scope changes of projects, ineffective requirements, ineffective strategic alignments, insufficient funds, lack of user involvement, lack of shared missions and accountabilities, and lack of IT involvement in corporate strategy formation. Information technology executives could establish "organizational development (OD) roles" (N. Evans \& Hoole, p. 1) to improve fusion. A. Evans (2003) and N. Evans and Hoole recommended that future research should explore strategies for promoting business-IT fusion.

The business-IT gap is a problem that affects organizational performance (A. Evans, 2003; N. Evans, 2004a, 2004b). According to Frank, Mobs, Son, and Wagner (2004), organizational performance and profitability depend on business processes. Business processes rely on IT. Therefore, profitability and performance of companies depend on business-IT fusion.

\section{Statement Of The Problem}

The Standish Group (2004) found $29 \%$ of IT projects succeeded, $18 \%$ of projects completely failed, and $53 \%$ partially failed because they were either over budget or did not meet quality standards. The finding indicates $71 \%$ of IT projects did not meet all project goals. A. Evans (2003) and N. Evans (2004a, 2004b) determined that poor information systems (IS) lead to failures that cost the industry about $\$ 100$ billion per year. In addition, businesses continue spending a marginal cost from "1.5 to 3.5[\%] of revenue across most industries" (Britt, 2002, p. 1) on IT but they are seldom effectively managing and optimizing the expected return on investment (ROI).

Organizations tend to have difficulty managing IT applications and related business processes (Anderson \& Weiss, 2004; Bygstad, 2004) such as the managerial leadership aspects between business and IT units (N. Evans, 2004b; Hatzakis, 2004). They find it difficult to minimize risks and optimize performance (Shere, 2004).

\section{Significance Of The Study To Leadership}

Many problems intrinsically associated with human and organizational factors that encourage IT research shift from a technology focus to a managerial and organizational focus (N. Evans \& Hoole, 2005). Examples include promoting fusion, establishing IT governance, and implementing collaborative organization. Schein (2004) posited leaders form cultures and cultures affect leaders. Information technology executives can promote a culture that supports business-IT fusion (N. Evans \& Hoole). When establishing and implementing business-IT fusion, organizational development roles, IT governance, and collaborative organization are key strategies for capturing new business opportunities, mitigating risks, improving ROI, and supporting managerial leadership effectiveness (Coughlan, Lycett, \& Marcredie, 2004; A. Evans, 2003; N. Evans, 2004a, 2004b; N. Evans \& Hoole, 2005; Haes \& Grembergen, 2005; Hatzakis, 2004). 


\section{Theoretical Framework Of The Study}

Approximately 2400 years ago, Chinese general Sun Tzu posited those who master all the skills of war win; those who do not are defeated (Tzu, 1983 version). Sun Tzu alluded to how management planning skills are crucial for creating synergy to solve a problem. However, changes in the business environment may force theories to evolve to be effective. For example, management theories have evolved from Scientific Management by Frederic Taylor (1911), to Human Relations Movement by Elton Mayo, to Statistical Quality Control by Charles Protzman, Homer Sarasohn, and Edwards Deming (Perry, 2005; Wren, 1994), thus allowing organizations to shift their focus from operational efficiency to organizational effectiveness and to quality control. Similarly, management has been shifting from a focus on the stockholder to a focus on the stakeholder (Mason-Riseborough, 2003), making the notion of profit apply not only to owners, but to employees, partners, and communities. Management of IT has also evolved, shifting from an almost exclusively technical focus to include organizational and managerial matters (N. Evans \& Hoole, 2005). Some existing IT management strategies may need to be revised to address new requirements.

\section{REVIEW OF THE LITERATURE}

Research has shown a broad range of historical perspectives that include scientific management, human relations movement, statistical quality control management, total quality management (TQM), Six Sigma methodology, project and IT management, agency theory, stakeholder theory, and ethical theory. Management practices promote efficiency and quality and describe management responsibilities toward owners, stakeholders, business units, programs, and end users. Management theories continue to be a foundation for modern management practices. Historical and philosophical developments in the field are described to reflect an adequate knowledge about managerial leadership practices that demonstrate fusion in work relationships.

Innovation in technologies has transformed a largely agricultural society to a commercial development society engaged increasingly in manufacture with the creation of large factories (Scott, 2003; Wren, 1994; Yan, 2006). History indicates developments in both management and engineering were required to adapt to change (Scott; Wren). Managing factories and resources efficiently required new methods of work, production, and payment. Frederick Taylor provided credibility to the idea of scientific management (Wren). Engineers promoted the standardization of mechanical parts and Taylor divided the human elements in production into their smallest units to determine a best way to perform each job (Taylor, 1911). The result was that control of productivity became part of scientific management. Taylor concluded one best method existed to achieve the maximum surplus.

Innovation in IT has transformed organizations from industrial factory manufacture to diverse networks enabled by IT (Hassard, 1993). The transformation indicates the "viability of organization as a closed system has been challenged" (Yan, 2006, p. 6). According to Maxcy (1994), organizations behave as an "organic community" rather than a "mechanical phenomenon" (p. 129). Although Yan purported individuals are homogeneous under scientific management practices, the view does not promote individualism or allow individuals to position themselves at their full potential. Organizational structures should not limit human factors. Because human factors are resources, organizations should enable individuals to transform existing structures to achieve fusion and competitive advantage (Yan).

From the beginnings of scientific management to the modern age of IT, there have been large technological advancements in the tools and equipment used for production. Indeed, the same can be said for changes in the business process and skill sets required of the present-day environments. An example is the cost and inefficiency of conducting business face to face in the marketplace. The Internet provides a virtual environment that eliminates costs and makes business encounters almost instantaneous. A firm has a competitive advantage or values creation because it uses resources more effectively or owns more efficient resources than its competitors do (Kunin, Kunin, \& Rumelt, 2003; Penrose, 1959). Competitive advantage has prompted organizations to seek better and more efficient ways of managing their IT resources. More organizational leaders are looking at standardization models for answers to some of their problems (Strassmann, as cited in "Letter to the Editor," 2003). Specifically, standardization provides cost-effective models for IT. 
Bill Gates's vision spurred the proliferation of the personal computer as a valuable tool in homes and offices. Gates's contribution to the advancement of management theories lies in his use of computer technology and its application in solving business problems in a fraction of the time previously required (Gates, 1999). Windows operating systems and Microsoft Office software have revolutionized and partially standardized large and small office environments.

The majority of IT projects fail (Chen \& Latendresse, 2003; N. Evans, 2004a, 2004b). N. Evans (2004a, 2004b) posited communication problems between business and IT professionals are the cause of most IT project failures. Chen and Latendresse recommended that business professionals should learn more about certain technical aspects such as the automation of software tools to bridge the communication gap. N. Evans (2004a, 2004b) further posited the business analyst and the system analyst play important roles for achieving communication. In particular, the analysts must understand the requirements from the stakeholders. Effective collaboration requires analysts to exercise both technical and soft skills. The technical skills include programming, enterprise resources planning software, Java programming, database and quality management, and object-oriented development. The soft skills include strategic thinking, risk assessment, and communication. Regarding personal characteristics, analysts should be proactive and adaptive. Thus, N. Evans (2004a, 2004b) theorized business analysts must understand the technical issues. Similarly, system analysts must understand the business issues. Some of the business and system analysts' skills should overlap to bridge potential communication gaps.

According to Brook (2004), traditional project management may not be the right tool for IT project management. Brook emphasized that ensuring stakeholder participation is the critical factor for IT projects to be successful. Gillard (2004) noted that large matrix organizations should promote sound project management with the efficient use of resources. For large IT projects, management should incorporate three views: (a) a project office for the project team; (b) intraorganization for the parent organization, users, and contractors; and (c) interorganization for external organizations. According to Dinson (2003), organizations are probably just unsupported by real action to project management, which may be one of main reasons IT projects have been abandoned or have a high percentage of failure.

\section{FINDINGS}

The horizontal integration of disparate systems, applications, and processes that corroborated the studies of N. Evans and Hoole (2005), Haes and Grembergen (2005, 2006), and Coughlan et al. (2004) should show the following: (a) IT executives can design organizational development roles to improve organizational effectiveness, (b) the board and executives can design IT governance to guide and support processes and structures to meet organizational development roles, (c) organizational leaders can promote collaborative organization to support relationship management, (d) good working relationships between business and IT reduce business-IT gaps, and (e) shared ownership and responsibilities between business and IT contribute to risk mitigation, ROI, and organizational performance.

Some alternative propositions that disputed or extended the studies of N. Evans and Hoole (2005), Haes and Grembergen $(2005,2006)$, and Coughlan et al. (2004) should show best practices and strategies for organizations to do the following: (a) consider CIO as part of the executive team and recognize IT as key business functions; (b) define business-IT improvement, address goals and responsibilities, and support collaboration between IT and programs regularly; (c) mandate IT and program management to understand each other's needs and motivations; (d) align federation-based corporate cultures with strategic business-IT fusion; (e) support standardization toward enabling interoperability, COTS products, and total cost of ownership saving; (f) support harmonization toward advancing the program development and maximizing customer satisfaction; and (g) support a standard interface that all applications can link to.

The question was posed how managerial leadership practices effectively advance business-IT fusion of an inclusive and collaborative organization. The horizontal integration activity that occurred was apparently detectable through managerial leadership experiences and expectations. Efforts of consolidating common practices in IT and 
engineering and centralizing leadership across previously separated regional businesses help to eliminate redundancy in structures, applications, and processes.

The managerial leadership practices effecting transformation of the organization appeared to be primarily centered on the corporate level with additional regard for meeting customers' demands. The programs level, however, is still in a disparate mode that requires internal values streams to be integrated and aligned to the systems and capabilities of customers to maximize customer satisfaction. Information technology should continue to shift from services and solutions to realizing program goals. Consolidating common practices in IT and engineering and integrating core competencies to programs will optimize synergy. Applying managerial leadership at both corporate and programs levels of horizontal integration should improve the chance of success.

Organizational issues such as cultural and human aspects should be properly addressed during the horizontal integration of system development processes to allow knowledge to be transferred between IT and programs. Meaningful governance mechanisms should be defined and implemented across organization to complement the efforts of the individual contributors. Effective leadership principles should be demonstrated at all levels of responsibility to integrate and optimize organizational development roles, IT governance, and relationship management for business-IT fusion.

The business-IT relationship could be improved if the programs and IT treat each other as one team or partners instead as a type of adjunct. Defined charter, roles, and responsibilities help the team to establish effective communication channels, allowing business-IT units to gain necessary knowledge of each other's requirements. In addition, collocation with programs being supported was important for IT technical personnel because it enhances trust and understanding of complex technical and cultural issues. To build aforementioned core competencies, IT has to find the right people for the job to take lead roles according to their degree of specialization. IT units have to set the program's requirement above their own agenda. Greater standardization and dissemination of common businessIT processes and tools and development of an integrated systems engineering methodology to implement the corporate integrated enterprise process standard are necessary to provide practical solutions to enhance relationship management, mitigate risks, and improve ROI.

\section{SUMMARY AND RECOMMENDATIONS}

The journey to understanding the viability of business-IT fusion provides significant and substantive contributions toward the growing body of research regarding how to effectively organize business-IT fusion. Research has disclosed that integrating organizational development roles, IT governance, and relationship management was the preferred modality when promoted IT innovation to enhance collaborative and integrative aspects of the organization. Studies have substantiated the need for further research specific to the following research questions: (a) how organizations demonstrate business-IT fusion's contribution to the success of the enterprise, (b) how IT is situated as the enabler of change, and (c) how business-IT fusion facilitates organizational transformations. Finally, the research indicates a collaborative and integrative model is needed to gain further insights into and subsequently improve managerial leadership practices. Strategies to implement the collaborative and integrative model to large organizations can present significant challenges because of subcultures-bound; however, these challenges could yield greater organizational performance by enhancing the capabilities of leaders and employees within the organization.

\section{AUTHOR INFORMATION}

Dr. Than Lam is a Lead Member Engineering Staff for the Lockheed Martin Maritime Systems and Sensors at Moorestown with a research focus on Business-IT Fusion, Engineering Collaborative Applications, and Systems Modeling Language and Unified Modeling Language Tools. In addition, Dr. Lam serves as an Adjunct Professor at Green Mountain College. He has designed course modules and conducted distance learning for MBA courses: BUS 6010 Leadership, Values, and Decision Making and BUS 6110 Strategic Management of Nonprofit Organizations. He can be reached at lamthan@ greenmtn.edu. 
Dr. Ronald Black is a full-time research faculty member for the School of Advanced Studies at the University of Phoenix Online with a specific focus on research and dissertations. Dr. Black has served as a faculty member and vice president at five institutions of higher learning over the past 30 years. He has also conducted considerable research studies in technology and distance learning. Dr. Black's recent scholarship includes writings on educational and business alliances and speaking engagements at Oxford University and the United Nations. He can be reached at blackr@email.phoenix.edu.

\section{REFERENCES}

1. Anderson, D., \& Weiss, J. (2004, January 5-8). Aligning technology and business strategy: Issues \& frameworks, a field study of 15 companies. Paper presented at the 37th Hawaii International Conference on System Sciences, Big Island, HI. Retrieved February 17, 2006, from http://csdl2.computer.org/comp/proceedings/hicss/2004/2056/08/205680220c.pdf

2. Bowditch, J. L., \& Buono, F. (2001). A primer on organizational behavior. Hoboken, NJ: Wiley.

3. Britt, F. (2002). Multiplying business value: The fusion of business and technology. IBM Institute for Business Value. Retrieved August 1, 2005, from http://www935.ibm.com/services/uk/index.wss/summary/igs/a1007988

4. Brook, P. (2004). Constituents and their expectations: Towards a critical-pragmatic theory of information systems project management. Unpublished doctoral dissertation, University of Western Sydney, Australia.

5. Bygstad, B. (2004, January 5-8). Controlling iterative software development projects: The challenge of stakeholder and technical integration. Paper presented at the 37th Hawaii International Conference on System Sciences, Big Island, HI. Retrieved February 17, 2006, from http://csdl2.computer.org

6. Chen, J., \& Latendresse, P. (2003, March 6-8). The information age and why IT projects must not fail. Paper presented at the 34th Southwest Decision Sciences Institute Annual Conference, Houston, TX. Retrieved February 17, 2006, from http://www.swdsi.org/default.asp

7. Coughlan, J., Lycett, M., \& Macredie, R. (2004, January 5-8). Creating the collaborative organization: The promise of relationship management. Paper presented at the 37th Hawaii International Conference on System Sciences, Big Island, HI. Retrieved February 17, 2006, from http://csdl2.computer.org

8. Dinson, A. (2003). A systematic evaluation of information technology project managers and organizational project management maturity. Unpublished doctoral dissertation, Nova Southeastern University, Davie, Florida.

9. Evans, A. (2003). A framework for creating fusion in the business-IT interface. Unpublished doctoral dissertation, University of Pretoria, Pretoria, South Africa.

10. Evans, N. (2004a). Promoting fusion in the business-IT relationship. Journal of Issues in Information Science and Information Technology, 1, 303-311. Retrieved July 10, 2005, from http://proceedings.informingscience.org

11. Evans, N. (2004b). The need for an analysis body of knowledge (ABOK): Will the real analyst please stand up? Journal of Issues in Information Science and Information Technology, 1, 314-329. Retrieved July 10, 2005, from http://proceedings.informingscience.org

12. Evans, N., \& Hoole, C. (2005). Promoting business/IT fusion: An OD perspective. Leadership \& Organization Development Journal, 26, 310-325. Retrieved January 23, 2006, from http://www.emeraldinsight.com

13. Frank, J., Mobs, A., Son, S., \& Wagner, H. (2004). Bridging the gap: Linking IT-infrastructure and business processes. Frankfurt, Germany: Johann Wolfgang Goethe University. Retrieved June 22, 2006, from http://www.wiiw.de/publikationen/BridgingthegapLinkingITInfra1132.doc

14. Gates, B. (1999, March 22). Bill Gates' new rules. Time.com, 1-4. Retrieved September 1, 2004, from http://www.time.com/time/reports/gatesbook/gatesbook1.html

15. Gillard, S. (2004). IT project management: A conceptual view. The Journal of American Academy of Business, Cambridge, 5, 381.

16. Haes, S., \& Grembergen, W. (2005, Jan. 3-6). IT governance structures, processes and relational mechanism: Achieving IT/business alignment in a major Belgian financial group. Paper presented at the 38th Hawaii International Conference on System Sciences, Big Island, HI. Retrieved February 17, 2006, from http://csdl2.computer.org/comp/proceedings/hicss/2005/2268/08/22680237b.pdf 
17. Haes, S., \& Grembergen, W. (2006, Jan. 4-7). Information technology governance best practices in Belgian organizations. Paper presented at the 39th Hawaii International Conference on System Sciences, Kauai, HI. Retrieved June 22, 2006, from http://www.computer.org

18. Hassard, J. (1993). Sociology and organizational theory: positivism, paradigms, and postmodernity. Cambridge, England: Cambridge University Press.

19. Hatzakis, T. (2004). A social capital approach to IT relationship management evaluation. London, United Kingdom: Brunel University, Department of Information Systems and Computing.

20. Kunin, E., Kunin, H., \& Rumelt, R. (2003). What in the world is competitive advantage? (Policy Working Paper 2003). Los Angeles: University of California, The Anderson School. Retrieved January 12, 2006, from http://www.anderson.ucla.edu

21. Mason-Riseborough, G. (2003, May 23). Stockholders and stakeholder theories: An analysis. Retrieved October 1, 2004, http://www.geocities.com/griseborough/55.htm

22. Maxcy, S. J. (1994). Postmodern school leadership: meeting the crisis in educational administration. Westport, CT: Praeger.

23. Penrose, E. T. (1959). The theory of the growth of the firm. London: Basil Blackwell.

24. Perry, J. (2005). W. Edwards Deming-An overview. Paper presented at the Ontario Public Sector Quality Fair, Toronto, Ontario, Canada. Retrieved January 12, 2006, from http://www.psqf.org

25. Schein, E. (2004). Organizational culture and leadership (3rd ed.). San Francisco: Jossey-Bass.

26. Scott, W. R. (2003). Organizations: Rational, natural, and open systems (5th ed.). Upper Saddle River, NJ: Prentice Hall.

27. Shere, S. (2004, January 5-8). Managing risks beyond the control of IS managers: The role of business management. Paper presented at the 37th Hawaii International Conference on System Sciences, Big Island, HI. Retrieved February 17, 2006, from http://csdl2.computer.org/comp/proceedings/hicss/2004/2056/08/205680220a.pdf

28. Standish Group. (2004). 2004 third quarter research report. Retrieved July 31, 2006, from http://www.standishgroup.com

29. Taylor, F. (1911). Principles of scientific management. New York: Harper and Row.

30. Tzu, S. (1983). The art of war, translated by James Clavell. New York: Delacorte Press.

31. Welsh, E. (2002, May). Dealing with data: Using NVivo in the qualitative data analysis process. Qualitative Social Research, 3(2), 1-7. Retrieved April 21, 2007, from http://www.qualitativeresearch.net/fqs-texte/2-02/2-02welsh-e.htm

32. Wren, D. A. (1994). The evolution of management thought (4th ed.). New York: Wiley.

33. Yan, T. (2006). Organizational improvisation: An alternative way of conceptualizing partnership and teacher leadership that facilitates efficiency and accountability without the expense of ownership. Tai Po, New Territories, Hong Kong, The Hong Kong Institute of Education. Retrieved June 28, 2006, from http://k1.ioe.ac.uk/May2006/Papers/TangWaiYanRonald_Paper.doc 
NOTES 